Article

\title{
Diversity Management as a Tool for Sustainable Development of Health Care Facilities
}

\author{
Nadežda Jankelová, Zuzana Joniaková, Katarína Procházková *(i) and Jana Blštáková(i) \\ Department of management, Faculty of business management, University of Economics in Bratislava, \\ 85235 Bratislava, Slovakia; nadezda.jankelova@euba.sk (N.J.); zuzana.joniakova@euba.sk (Z.J.); \\ jana.blstakova@euba.sk (J.B.) \\ * Correspondence: katarina.prochazkova@euba.sk; Tel.: +421-907-427-424
}

Received: 18 May 2020; Accepted: 24 June 2020; Published: 27 June 2020

\begin{abstract}
Organizations providing health services are often criticized because of inadequate and unsuitable management processes or procedures. Today's challenge is focused on effective management and leadership skills in the area of health care. The aim of the research is to describe, analyze, and evaluate the current state of diversity management in details in the context of human resources management in the selected healthcare facilities. The source of the information was a questionnaire survey. The sample consists of 181 managers from various health care and health service organizations. The method of analysis of variance (ANOVA) was used for data processing. The results were processed in SPSS and Excel programs. Pearson's coefficient was used to evaluate the cross-correlation of the variables. The level of significance was $5 \%$ on both sides. Basic awareness of diversity management in the healthcare facilities is low. Some tools of diversity management are used, but only in isolation, non-conceptually, and unsystematically. The acknowledgment of diversity concept is poor and chaotic. The basic models of this concept defining its goals, activities, programs, responsibilities, and measurements are not known. One of the strong areas of the diversity management in the healthcare facilities is the diversity of working teams. On other hand, the weak side is the diversity as part of the organization culture and diversity as a part of human resource management. The summarizing index Attitudes towards Diversity received a higher average value than the Diversity Management Implementation index. Significant variables influencing the level of aggregate indices were identified: Ownership, size of the organization in terms of number of employees, patients' satisfaction, and employees' satisfaction.
\end{abstract}

Keywords: diversity management; human resources management; healthcare; diversity attitudes; diversity management implementation

\section{Introduction}

Sustainability and sustainable development are concepts that are not just relevant in the context of global change of environment, but can be increasingly found in the visions and long-term goals of many organizations in the profit and non-profit sectors. The basis for achieving the sustainable development of these organizations is management itself and its ability to respond proactively to the external/internal threats and opportunities via application of effective managerial tools. Healthcare is a sector that is very sensitively perceived by the population, as the topic of individual and public health is at the forefront of human needs. At this time of the Covid-19 Pandemic, when basic human health protection has come back into the spotlight, we all perceive that only viable health care facilities managed by high quality management teams can professionally handle the state of emergency we are in and can be a high quality provider of health care services in the post-pandemic period. 
One of the preventive managerial tools that can be applied to provide a smooth business operation is the diversity management. Global demographic trends and increasing variability of the workforce market point out the necessity to apply the diversity management in the whole spectrum of business. The typical diversity elements: Gender, nationality, health disabilities, and age, are being extended by new ones: Experience, personality, priorities, attitudes, communication styles, working behavior, and communication capabilities.

In health care, in the provision of health care services, organizations employ a diverse workforce. In many cases, they are managed by managers-top experts in the field of medicine, but less so by experts in the field of management. They carry out management practice based on experience, or through their own trials and errors, or in the best case, they also complete managerial training as part of lifelong learning. However, qualified and innovative management is still insufficient in this sector. Pihlainen, Kivinen, and Lammintakanen [1], Ackerly et al. [2], Enterkin et al. [3], and Yoder-Wise [4] state that the need for leadership and leadership skills in healthcare sector is a current challenge. Approaches to the development of health care managers have been reported as inadequate and contradicting $[2,5,6]$. Management and leadership roles go beyond the scope of the doctor's typical role; management and leadership competence have been shown to be insufficient in many studies $[7,8]$.

The aim of our research is to describe, analyze, and evaluate in more detail the current state of diversity management in the context of human resource management in selected health care facilities. In the context of the Slovak Republic, this research is original, because according to our best knowledge, there are no studies or scientific literature that would transfer the theoretical topic of effective diversity management into the practice of health care providers. However, many of the stated studies from other backgrounds confirm that diversity management has a major impact on the performance of organizations. We therefore consider it important to examine this phenomenon in the conditions of the Slovak healthcare system.

At the same time, there are many studies conducted abroad (outside of Slovakia) stating the positive relationship between diversity management and the specific outcomes on healthcare facilities, especially its patients, internal staff, or external interest groups. The importance of diversity management in relation to the improved outcomes has been documented in the treatment of children's asthma [9], in the treatment of diabetes [10], in improvement of the quality of patient care [11], in the implementation of patient-oriented healthcare [12], in increasing patient safety, and reducing clinical errors [13,14].

In relation to employees, to increase their satisfaction and commitment, and consequently to increase the quality of services provided by them, there are negative findings of many studies on the low implementation of diversity management tools, but on the other hand, many studies point out to the highly positive results of this tool in the context of human resources management.

The report 2014 prepared by the American Hospital Association provides insight into issues of diversity in this environment [15]. It states that the generational diversity is rapidly changing the workforce dynamics. Each generation has its own priorities, attitudes, communication styles, work approaches, and ways of communicating with colleagues that affect organizational culture and performance. At the same time, it recommends that each organization launch an intergenerational evaluation to determine the organization's workforce profile and develop a comprehensive plan; implement targeted recruitment, segmented retention, and succession strategies and development of tailor-made communication strategies that cultivate the understanding and sensitivity of generations.

A study by Cook and Bartram [16] states that, given the general pressure to reduce costs and the need for high-quality care in the healthcare and elderly care sectors, effective workforce management in organizations in these sectors is critical. In their article, they examined the changing health care environment and care systems for the elderly, and identified key challenges in the field of human resource management, as they identified it as the most significant weaknesses in this area. According to the authors, human resource management systems in the healthcare sector are not able to provide meaningful employee development, and employees are concerned about the invasion of performance-based culture into management itself. Based on their findings, the authors argue that 
aligning care ethics with business efficiency can be extremely problematic. The upward communication was also identified as a weak point due to hierarchical structures constraints and a lack of opportunities. They emphasize two features of the professional work environment: The position of the hierarchy, and the professional diversity of employees. These environmental characteristics are sources of situational constraints in behavior. They argue that interdisciplinary and interprofessional strength and status have important implications for human resources practice under the condition the knowledge chain is to be uninterrupted via a sound diversity management in the area of workforce professional background, age, gender, and other factors.

Kossek, Lobel, and Brown [17] found out that working groups with greater gender diversity have a more favorable attitude towards organizational efforts related to diversity management. This significantly applies also to the healthcare sector as published Horwitz, Sonival, and Horwitz [18]. At the same time, they pointed out that the increase in the proportion of women in the top management is associated with a decrease in stereotypes. Büchner, Schreyögg, and Schultz [19] analyzed the interaction effects of board diversity and board activity level in German hospitals.

Baraias [20] describes ways to use diversity in human resource management in the healthcare sector to improve patient care. These are various innovative strategies for attracting talent across generations, targeted efforts to recruit employees of different generations, application of social media in hiring, and diversity leadership. The diversity leadership contributes to the performance of an organization by removing obstacles in communication, increasing innovative ideas, and reducing stereotypes [21]. It promotes fruitful collaboration in different teams [22,23] and enables inclusion not only in teams, but also in organizations [24-26]. Inclusive leadership is considered beneficial in facilitating and promoting the feeling of belonging and uniqueness [27]. However, Ashikali, Groeneveld, and Kuipers [28] point out that diverse or inclusive leadership helps to promote an inclusive climate, as greater diversity of teams does not automatically create an inclusive environment. Inclusive leadership is therefore crucial to promoting inclusion in different teams.

The existing literature defines diversity management as a multifaceted concept, encompassing managerial activities that promote workforce diversity, recognize diversity as an important organizational goal, build cultural awareness, and ultimately adopt and implement formal diversity programs [29]. Dreachslin et al. [30] identifies three key areas related to the definition of diversity management. According to them, diversity must be recognized, at the same time it must be managed, and reducing disparities can improve organizational performance. The author presents five competencies in the field of strategic diversity management, namely diversity leadership, strategic human resource management, organizational culture, diversity culture, and the cultural competence of patients. Weech-Maldonado et al. [31] complement them with health care delivery mechanisms and community involvement. Choi [32], Opstrup and Villadsen [33], and Johansen and Zhu [34] also consider these competencies to be important, as they consider a diversity culture to be a certain stage of development in which the organization is committed to diversity-friendly management practices. These are, for example, procedures in human resource management (recruitment, training, mentoring), in the field of leadership, in order to appreciate all demographic groups.

Recruiting a diverse workforce is one of the main ways to help jobseekers see an organization as a positive place to work [35]. Diversity training programs are often designed to alleviate conflicts between members of an organization, to understand and understand each other, and to improve the performance of teams and the organization as a whole [36].

The main principle of diversity management is a systemic approach, and becomes an advantage for all members of the organization when it's systematically activated in the organization and receives positive attention [37].

Most of the existing research analyzes show diversity management effects work groups and organizational performance, job satisfaction, employee engagement, workforce stability, organizational performance, innovation, competitiveness, and work climate [27,38-44]. 
The importance of diversity management in healthcare is highlighted by Horwitz and Horwitz [38], who, based on the analysis of various 35 diversity studies, concluded that diversity of functional areas (e.g., finance, marketing, information technology) and educational diversity have a positive impact on team performance, while bio-demographic diversity (such as racial, ethnic, or gender diversity) does not have this effect. Their research, as well as that of other authors [45-47], emphasize demographic diversity can be an advantage if it can be managed effectively. Galbraith [48] states that for the successful implementation of diversity management, it is necessary to create diversity leadership groups in hospitals that coordinate activities locally and support a systemic view in respecting and accepting local culture. Diversity management emphasizes involvement of all company levels in diversity training.

Healthcare systems distinguish between two concepts-diversity management and cultural competency. Dreachslin et al. [30], Watters, Bergstrom, Sandefer [49], and Weech-Maldonado et al. [31], see this difference in the fact that diversity management is generally concerned with the management of human resources and other practices related to the recruitment and retention of the workforce, while cultural competence in health care concerns the ability of systems, organizations, and staff to meet the needs of diverse patients, families, and communities. In other industries, both concepts are being merged into one system with focus on internal customers-employees, but also on external customers [50].

The authors analyze different types of diversity (primary diversity in terms of age, gender, nationality, racial or ethnic origin, disability, sexual orientation, but also secondary diversity such as education, marital status, religion, work experience, organizational role and level, and others that form an important role in creating a person's value orientation, his or her life experiences and expectations) and diversity management according to individual organizational levels (individual, team and organizational level). In addition to standard implemented types of diversity such as race, gender, ethnic, age, etc. and their contributions to various key variables of organizations, such as increasing the rate of innovation, increasing competitiveness, improving the working climate and employee satisfaction, and increase in engagement [37-40,42], other types of diversity are also explored. Specifically, cognitive diversity, defined as the inclusion of people who have different ways of thinking, different viewpoints, and different skill sets in a team or business group, is considered [51-53]. Research has shown a positive relationship between cognitive diversity and innovation management with the aim of processes improvement [52] as well as greater social interaction in the diversity team and its greater creativity [54]. Additionally, political, intellectual, and psychological diversity is being mentioned with its impact on various social environments with its unique attributes. Their effective grasp and acceptance of an organizational culture that includes standards of acceptance of differences is becoming a recognized requirement of lasting competitive advantage $[44,55]$. Schaffer [44] states that via team membership in diversity, teams gain a feeling of belonging, and fellowship with the group is being strengthened as well as individual feelings of self-esteem. However, Shaffer [44] also points out that over-focusing on diversity and perceiving differences from others can have many negative consequences in terms of negative attitudes and employee behavior.

Genkova and Schuster [56] mentioned some disadvantages, e.g., feelings of threat and vulnerability, long decision-making processes and low cohesion, negative working atmosphere, and inefficient work performance. Many other studies [57] also identified the differences between various types of diversity and their relationship to organizational performance. Racial diversity and ownership diversity have positive relationships to organizational performance, while functional diversity has a negative relationship. Their further analysis reveals that climate diversity positively mitigates the relationships between racial diversity, functional diversity, ownership diversity, and organizational performance.

The diversity of attitudes, values, and personalities [58] is important in the management of the working group and is reflected in work results, overall working attitude, or employee turnover. In their research, Hafsi and Turgut [59] demonstrated a significant relationship between the diversity of a company's board of directors, measured by two variables, namely the index for the diversity of 
boards (board size, leadership duality, director's independence, his experience) and the index for the diversity in boards (age, ethnicity, term of office) and social performance. This was quantified by using forty-three different social performance indicators, selected from seven categories-community, corporate governance, diversity, employee relations, environment, human rights, and social issues related to products.

Diversity is the subject of research at the enterprise level, at the team level $[22,54,60]$, as well as at the department and individual levels [61,62]. Opinions on the positive relationship of diversity on team's performance are not always clear, because the positivity is conditioned by several factors. Hoever, I. J. et al. [54] point out that team diversity may not be in all cases associated with higher team creativity. They found out that the higher creativity of a heterogeneous team is conditioned by the perception of the perspective of other team members, the understanding of their motives, thoughts, feelings, reasons, i.e., social interaction.

Dahlke, Stahlke, and Coatsworth-Puspoky [63] researched team diversity and teamwork in relation to the job satisfaction of healthcare sector professionals, Havig, Skogstad, Veenstra, and Romøren [13], Kalisch and Lee [64], and Kurowski, Gore, Buchholz, and Punnett [14] found out that effective teamwork, including its diversity aspects, reduces clinical errors, increases the quality of healthcare, and increases patient safety. Havig et al. [13] condition these results by self-government of diversity teams.

Research also focuses on examining the diversity of top management in different contexts [65-67]. The findings point out to the positive effects in relation to performance of teams operating on a short-term basis, and reversely, to negative effects on teams operating on a long-term basis.

The connection between the nature of team processes (cooperative behavior, accurate exchange of information, and decentralization of decision-making) in the top management team and team diversity was also confirmed. The characteristics and functional background of top managers and the performance of top management teams interact positively in improving the performance of organizations.

Schaffer [44] points out that the implications of all research for management depends on the idea that understanding these processes can have real and significant effects on team dynamics and related competitive advantages. He states that diversity in the workplace is currently the new standard in business, not the exception, and that the synergies coming from diversity in problem solving are seen as an important source of competitive advantage for many employers. It is clear that existing theory and research in the area of diversity, together with evidence highlighting the shift in societal and organizational norms, supports the continued development and penetration of research highlighting the benefits of diversity management also in many other fields.

\section{Materials and Methods}

For purpose of our research, we used a questionnaire, which we distributed to representatives of selected health care facilities. Our questionnaire was created to map the situation in the field of diversity management in health care facilities in Slovakia. The questionnaire consisted of an identification part and a core survey part. The survey was distributed throughout Slovakia; respondents covered western, central, and eastern Slovakia, and all types of healthcare facilities. The questionnaire survey took place in 2019 from April until November. The survey was sent by e-mail to representatives of selected organizations in various managerial positions depending on the willingness to cooperate in research. The second possibility of distributing the questionnaires was a personal meeting with representatives of organizations, either at their workplace or as part of their participation in specialized studies focused on health management and finance, organized by Slovak medical university in Bratislava.

After processing the questionnaires, checking their completeness and accuracy, we obtained a total of 181 full-fledged questionnaires, filled in by representatives of various types of health care providers (in institutional care-university hospitals, highly specialized specialist institute, general hospital, in outpatient care-polyclinic, general and specialized outpatient clinics/ambulances, day care facilities). The organizations varied in size according to the number of employees, the legal form, 
market presence, ownership, and the finance management: Economic results for the last 5 years, reported as profit or loss. Managers differed in managerial position, completed education (medical and other), and completed specialized studies-management minimum-MPH: Master of Public Health (Table 1).

Table 1. Socio-economic characteristics of the research sample.

\begin{tabular}{|c|c|c|c|c|c|c|c|}
\hline Variables & Category & F & $\mathbf{P}$ & Variables & Category & F & $\mathbf{P}$ \\
\hline Type of healthcare facilities & $\begin{array}{l}\text { university hospital } \\
\text { highly sp. institute } \\
\text { healthcare clinic } \\
\text { general hospital } \\
\text { special ambulance } \\
\text { day care facility. } \\
\text { Sum }\end{array}$ & $\begin{array}{l}17 \\
21 \\
40 \\
49 \\
44 \\
10 \\
181\end{array}$ & $\begin{array}{l}9.4 \\
11.6 \\
22.1 \\
27.1 \\
24.3 \\
5.5 \\
100.0\end{array}$ & $\begin{array}{l}\text { Number } \\
\text { of employees }\end{array}$ & $\begin{array}{l}\text { micro } \\
\text { small } \\
\text { middle } \\
\text { big } \\
\text { Sum }\end{array}$ & $\begin{array}{l}40 \\
13 \\
81 \\
47 \\
181\end{array}$ & $\begin{array}{l}22.1 \\
7.2 \\
44.7 \\
26.0 \\
100.0\end{array}$ \\
\hline $\begin{array}{l}\text { Legal } \\
\text { form }\end{array}$ & $\begin{array}{l}\text { joint stock com. } \\
\text { NGO } \\
\text { contributory } \\
\text { limited company } \\
\text { Sum }\end{array}$ & $\begin{array}{l}68 \\
7 \\
13 \\
93 \\
181\end{array}$ & $\begin{array}{l}37.5 \\
3.9 \\
7.2 \\
51.4 \\
100.0\end{array}$ & Market presence & $\begin{array}{l}\text { Under } 1 \text { year } \\
1-5 \text { years } \\
6-10 \text { years } \\
\text { Over } 10 \text { years } \\
\text { Sum }\end{array}$ & $\begin{array}{l}2 \\
10 \\
68 \\
101 \\
181\end{array}$ & $\begin{array}{l}1.1 \\
5.5 \\
37.6 \\
55.8 \\
100.0\end{array}$ \\
\hline Ownership & $\begin{array}{l}\text { private } \\
\text { public } \\
\text { Sum }\end{array}$ & $\begin{array}{l}99 \\
82 \\
181\end{array}$ & $\begin{array}{l}54.7 \\
45.3 \\
100.0\end{array}$ & $\begin{array}{l}\text { Education } \\
\text { level of } \\
\text { respondent }\end{array}$ & $\begin{array}{l}\text { Ing. } \\
\text { MUDr. } \\
\text { PhaRmDr. } \\
\text { Sum }\end{array}$ & $\begin{array}{l}20 \\
160 \\
1 \\
181\end{array}$ & $\begin{array}{l}11.0 \\
88.4 \\
0.6 \\
100.0\end{array}$ \\
\hline $\begin{array}{l}\text { Position } \\
\text { of respondent }\end{array}$ & $\begin{array}{l}\text { executive manager } \\
\text { deputy } \\
\text { superintendent } \\
\text { director } \\
\text { Sum }\end{array}$ & $\begin{array}{l}54 \\
18 \\
2 \\
107 \\
181\end{array}$ & $\begin{array}{l}29.85 \\
9.95 \\
1.1 \\
59.1 \\
100.0\end{array}$ & $\begin{array}{l}\text { Completed } \\
\text { management } \\
\text { minimum }\end{array}$ & $\begin{array}{l}\text { yes } \\
\text { no } \\
\text { Sum }\end{array}$ & $\begin{array}{l}123 \\
58 \\
181\end{array}$ & $\begin{array}{l}68.0 \\
32.0 \\
100.0\end{array}$ \\
\hline $\begin{array}{l}\text { Finance management } \\
\text { (number of profit years for } \\
\text { the last } 5 \text { years) }\end{array}$ & $\begin{array}{l}0 \\
1 \\
2 \\
3 \\
4 \\
5 \\
\text { Sum }\end{array}$ & $\begin{array}{l}1 \\
46 \\
92 \\
27 \\
6 \\
9 \\
181\end{array}$ & $\begin{array}{l}0.6 \\
25.4 \\
50.8 \\
14.9 \\
3.3 \\
5.0 \\
100.0\end{array}$ & & & & \\
\hline
\end{tabular}

Source: Research results. (F-Frequency, P-Percent).

The method of analysis of variance (ANOVA) of dependent variables on selected factors was used for data processing. SPSS and Excel programs were used to process the results. The correlation of the variables was evaluated using the Pearson coefficient. The significance level was 5\% bilaterally.

When looking for answers to the research, we proceeded from the following procedure. We divided the questionnaire into several thematic areas, each of which contained several questions (scaled and dichotomous). The questions were designed so that respondents for each question evaluate their own attitudes to diversity (expressing how they lean towards solutions in accordance with a diversity-based approach) and the degree of diversity implementation (as respondents implement and actually apply diversity in their own workplace). We created a complex index of diversity, consisting of selected items, while items with an attitude rating scale were scored ascending/descending (according to the meaning of the question), items with multiple answers were scored according to the number of marked options.

The Diversity Attitudes Index was compiled from 8 items, the Diversity Implementation Index also included 8 items, which were, after scoring and summarizing, subsequently divided by the highest achievable number of points and thus converted variables rated on a scale of $0-100$ (see Appendix A: Table A1-The scoring system of selected items). After testing reliability, the Cronbach's alpha of "Attitudes toward diversity" was 0.944 (54 elements) and the Cronbach's alpha of the "Diversity implementation" was 0.621 (20 elements).

We worked with these variables on research questions and examined their relationship with respect to the organization's identification data (i.e., size, ownership, and finance management), 
trend in employee satisfaction, and trend in patient satisfaction. We have identified the following research questions:

1. Are managers' attitudes towards diversity dependent on the type of organization in terms of the type of provided healthcare, its market presence, ownership, size according to the number of employees, and the legal form of the organization? Is there a demonstrable relationship between managers' attitudes towards diversity and employee turnover, employee satisfaction, patient satisfaction, and the economic results of the individual facilities they manage?

2. Is the degree of diversity management implementation dependent on the type of organization in terms of the type of healthcare services, market presence, ownership, size according to the number of employees, and the legal form of the organization? Is there a demonstrable relationship between the degree of diversity management and its implementation and employee turnover, employee satisfaction, patient satisfaction, and the economic results of the healthcare facilities?

\section{Results}

In the conditions of health care facilities in Slovakia, diversity management is applied only through partial tools, often unknowingly, with no knowledge of its benefits and possibilities. Based on the above, we focused our research on mapping the situation in this area by constructing a set of questions related to diversity management and based on respondents answers we examined two summary variables: Attitudes to diversity (which we wanted to find out the knowledge and perception of this issues) and the diversity implementation (by which we found out the steps actually taken in diversity management). We worked with these variables on research questions afterwards.

\subsection{Research Question 1}

Are managers' attitudes towards diversity dependent on the type of organization in terms of the type of provided healthcare, its market presence, ownership, size according to the number of employees, and the legal form of the organization?

Is there a demonstrable relationship between managers' attitudes towards diversity and employee turnover, employee satisfaction, patient satisfaction, and the economic results of the individual facilities they manage?

When looking for answers to research questions, we tested whether there is a statistical relationship between the aggregate variable "Managers' attitudes towards diversity" and variables-type of organization in terms of type of healthcare provided, market presence, ownership, size by number of employees, and legal form, employee turnover, employee satisfaction, patient satisfaction, and the economic result of individual facilities. The result is stated in Table 2.

The variables of ownership and size of the organization in terms of number of employees were identified as statistically significant $(p<=0.05)$. Insignificant variables are completed specialization studies in the field of management, employee turnover, and patient satisfaction $(p>0.05)$.

For the variables that were significant (ownership and size of the organization in terms of number of employees), we applied appropriate contrasts of categories. This allowed us to compare the differences between the categories and thus find out the direction of the influence of the independent variable on the dependent. We illustrate the results with graphs and tables of the estimated level of the dependent variable broken down by category. The overall level of attitudes to diversity on a scale of 0-100 (mean), its standard error (Std.Error), and the confidence interval are stated in Table 3. 
Table 2. Effects of independent variables (Tests of between-subjects effects, dependent variable: Attitudes_diversity).

\begin{tabular}{cccccc}
\hline Source & Type III Sum of Squares & df & Mean Square & F & Sig. \\
\hline Corrected Model & $30,975.802$ & 14 & 2212.557 & 245.721 & 0.000 \\
Intercept & $26,326.778$ & 1 & $26,326.778$ & 2923.784 & 0.000 \\
Ownership & 8247.441 & 1 & 8247.441 & 915.939 & 0.000 \\
Size & 94.369 & 3 & 31.456 & 3.493 & 0.017 \\
Spec_study & 0.645 & 1 & 0.645 & 0.072 & 0.789 \\
Employee turnover & 33.526 & 2 & 16.763 & 1862 & 0.159 \\
Employee satisfaction & 166.509 & 3 & 55.503 & 6164 & 0.001 \\
Patient satisfaction & 33.483 & 3 & 11.161 & 1239 & 0.297 \\
Finance management & 146.784 & 1 & 146.784 & 16.301 & 0.000 \\
Error & 1494.722 & 166 & 9.004 & & \\
Total & 681,170 & 181 & & & \\
Corrected Total & $32,470.524$ & 180 & & &
\end{tabular}

Table 3. Grand mean (Dependent variable: Attitudes_diversity).

\begin{tabular}{cccc}
\hline \multirow{2}{*}{ Mean } & \multirow{2}{*}{ Std. Error } & \multicolumn{2}{c}{$\mathbf{9 5 \%}$ Confidence Interval } \\
\cline { 3 - 4 } & & Lower Bound & Upper Bound \\
\hline 58.31 & 0.70 & 56.94 & 59.69 \\
\hline \multicolumn{3}{r}{ Source: Research results. }
\end{tabular}

Tables 4-9 show the structure of independent variables-ownership, size of the organization, completed specialization study of managers (MPH), employee turnover, employee satisfaction trend, patient satisfaction trend, and management.

The ownership factor was identified as significant $(p=0.0001)$. Private healthcare organizations have a higher level of attitude towards diversity. The size factor was also significant $(p=0.017)$. Attitudes towards diversity increase with the size of the organization (linear contrast).

Table 4. Attitudes towards diversity in organizations by ownership.

\begin{tabular}{|c|c|c|c|c|}
\hline \multicolumn{5}{|c|}{ Dependent Variable: Attitudes_Diversity } \\
\hline \multirow{2}{*}{ Ownership } & \multirow{2}{*}{ Mean } & \multirow{2}{*}{ Std. Error } & \multicolumn{2}{|c|}{ 95\% Confidence Interval } \\
\hline & & & Lower Bound & Upper Bound \\
\hline private & 70.54 & 0.75 & 69.05 & 72.02 \\
\hline public & 46.09 & 0.86 & 44.40 & 47.78 \\
\hline
\end{tabular}

Table 5. Attitudes towards diversity in organizations by size.

\begin{tabular}{ccccc}
\hline \multicolumn{4}{c}{ Dependent Variable: Attitudes_Diversity } \\
\hline \multirow{2}{*}{ Size } & Mean & Std. Error & \multicolumn{2}{c}{$\mathbf{9 5 \% \text { Confidence Interval }}$} \\
\cline { 3 - 5 } & & & Lower Bound & Upper Bound \\
\hline micro & 58.10 & 0.89 & 56.33 & 59.87 \\
small & 55.72 & 1.31 & 53.14 & 58.30 \\
middle & 59.44 & 0.78 & 57.90 & 60.97 \\
big & 59.99 & 0.84 & 58.34 & 61.64 \\
\hline \multicolumn{5}{c}{ Source: } \\
\end{tabular}


Table 6. Attitudes towards diversity in organizations by completed specialized management minimum.

\begin{tabular}{ccccc}
\hline \multicolumn{4}{c}{ Dependent Variable: Attitudes_Diversity } \\
\hline \multirow{2}{*}{ Specialized Minimum } & Mean & Std. Error & \multicolumn{2}{c}{$\mathbf{9 5 \%}$ Confidence Interval } \\
\cline { 4 - 5 } & & & Lower Bound & Upper Bound \\
\hline yes & 58.22 & 0.75 & 56.75 & 59.69 \\
no & 58.40 & 0.80 & 56.82 & 59.98 \\
\hline
\end{tabular}

Source: Research results.

Table 7. Attitudes towards diversity by employee turnover.

\begin{tabular}{ccccc}
\hline \multicolumn{5}{c}{ Dependent Variable: Attitudes_Diversity } \\
\hline \multirow{2}{*}{ Employee Turnover } & Mean & Std. Error & \multicolumn{2}{c}{$\mathbf{9 5 \% \text { Confidence Interval }}$} \\
\cline { 4 - 5 } & & & Lower Bound & Upper Bound \\
\hline $0-5 \%$ & 59.15 & 0.71 & 57.75 & 60.55 \\
$6-10 \%$ & 58.24 & 0.62 & 57.01 & 59.47 \\
$11-20 \%$ & 57.55 & 1.34 & 54.89 & 60.20 \\
\hline
\end{tabular}

Source: Research results.

Table 8. Attitude towards diversity and trend of employee satisfaction.

\begin{tabular}{ccccc}
\hline \multicolumn{5}{c}{ Dependent Variable: Attitudes_Diversity } \\
\hline \multirow{2}{*}{ Employee Satisfaction-trend } & Mean & Std. Error & \multicolumn{2}{c}{$\mathbf{9 5 \%}$ Confidence Interval } \\
\cline { 4 - 5 } & & & Lower Bound & Upper Bound \\
\hline unlisted & 56.69 & 0.61 & 55.50 & 57.89 \\
decreasing & 58.29 & 1.67 & 54.99 & 61.58 \\
not changing & 57.63 & 1.06 & 55.54 & 59.71 \\
increasing & 60.64 & 0.91 & 58.85 & 62.43 \\
\hline
\end{tabular}

Source: Research results.

Table 9. Attitudes toward diversity and trend of patient satisfaction.

\begin{tabular}{ccccc}
\hline \multicolumn{5}{c}{ Dependent Variable: Attitudes_Diversity } \\
\hline \multirow{2}{*}{ Patient Satisfaction-trend } & Mean & Std. Error & \multicolumn{2}{c}{$\mathbf{9 5 \%}$ Confidence Interval } \\
\cline { 4 - 5 } & & & Lower Bound & Upper Bound \\
\hline unlisted & 57.52 & 0.71 & 56.12 & 58.92 \\
decreasing & 58.21 & 1.38 & 55.50 & 60.93 \\
not changing & 58.70 & 0.76 & 57.21 & 60.20 \\
increasing & 58.82 & 0.93 & 56.99 & 60.64 \\
\hline
\end{tabular}

Source: Research results.

The specialized management minimum (MPH) was not a significant factor $(p>0.05)$. The employee turnover factor was not significant $(p>0.05)$, which means that management's attitudes towards diversity do not affect employee turnover.

The employee satisfaction factor was identified as significant $(p=0.001)$. Facilities that show an increase in the satisfaction of their own employees have a significantly higher level of attitudes towards diversity among managers than the average of other categories. The patient satisfaction factor was not significant $(p>0.05)$.

We also examined the area of attitudes towards diversity in relation to the economic results of the facilities we monitored over the last 5 years (2015-2019), with respondents stating whether they made a profit or a loss in the relevant year. We obtained the variable finance management as the number of years of profit (max. value 5). 
The dependence with the numerical variable finance management (i.e., the number of years in profit) was also significant $(p=0.0001)$. A positive coefficient $B=1.314$ in Table 10 means that this dependence is positive. It means that organizations with a higher level of attitudes towards diversity have been more profitable in the last 5 years.

Table 10. Attitudes towards diversity and finance management.

\begin{tabular}{ccccccc}
\hline \multicolumn{7}{c}{ Dependent Variable: Attitudes_diversity } \\
\hline \multirow{2}{*}{ Parameter } & \multirow{2}{*}{ B } & Std. Error & $\mathbf{t}$ & Sig. & \multicolumn{2}{c}{ 95\% Confidence Interval } \\
\cline { 5 - 7 } & & & & & Lower Bound & Upper Bound \\
\hline Intercept & 47.162 & 1.774 & 26.583 & 0.000 & 43.659 & 50.665 \\
Finance management & 1.314 & 0.325 & 4.037 & 0.000 & 0.671 & 1.956 \\
\hline
\end{tabular}

Source: Research results.

\subsection{Research Question 2}

Is the degree of diversity management implementation dependent on the type of organization in terms of the type of healthcare services, market presence, ownership, size according to the number of employees, and the legal form of the organization?

Is there a demonstrable relationship between the degree of diversity management implementation and employee turnover, employee satisfaction, patient satisfaction, and the economic results of the healthcare facilities?

In searching for answers to research questions, we tested whether there is a statistical relationship between the aggregate variable "Diversity management implementation" and variables-type of organization in terms of type of health care provided, market presence, ownership, size by number of employees, and legal form, employee turnover, employee satisfaction, patient satisfaction, and the economic result of facilities.

We obtained the aggregate variable "Implementation of diversity management" as the sum of points allocated for individual items expressing a higher degree of implementation of diversity. Subsequently, we divided the total number of points by the highest achievable number of points, thus obtaining a variable scaled from 0 to 100 .

Table 11 shows that, as in the first research question, significant variables are the type of ownership, the size of the organization according to the number of employees, but another important variable is patient satisfaction $(p \leq 0.05)$. Insignificant variables $(p>0.05)$ are other variables, namely completed specialization studies of the manager, employee turnover and satisfaction, as well as management. In the variables that were identified as significant, we introduced appropriate category contrasts. This allowed us to compare the differences between the categories and thus find out the direction of the influence of the independent variable on the dependent. We illustrate the results with tables of the estimated level of the dependent variable broken down by category. The total level of diversity management implementation on a scale of 0-100 (mean), its standard error (Std.Error), and confidence interval are given in Table 12.

Tables 13-19 show a structure by independent variables-ownership, size of the organization, completed specialized management minimum, employee turnover, employee satisfaction trend, patient satisfaction trend, and finance management. 
Table 11. Effects of independent variables on the variable "Diversity management implementation" (Tests of between-subjects effects dependent variable: Diversity_implementation).

\begin{tabular}{cccccc}
\hline Source & Type III Sum of Squares & df & Mean Square & F & Sig. \\
\hline Corrected Model & $15,002.228$ & 14 & 1071.588 & 14.255 & 0.000 \\
Intercept & $12,572.284$ & 1 & $12,572.284$ & 167.248 & 0.000 \\
Ownership & 823.849 & 1 & 823.849 & 10.960 & 0.001 \\
Size & 2976.684 & 3 & 992.228 & 13.200 & 0.000 \\
Spec_study & 88.178 & 1 & 88.178 & 1.173 & 0.280 \\
Employee turnover & 153.423 & 2 & 76.711 & 1.020 & 0.363 \\
Employee satisfaction & 473.181 & 3 & 157.727 & 2.098 & 0.102 \\
Patient satisfaction & 615.318 & 3 & 205.106 & 2.729 & 0.046 \\
Finance management & 222.026 & 1 & 222.026 & 2.954 & 0.088 \\
Error & $12,478.460$ & 166 & 75.171 & & \\
Total & $259,285.720$ & 181 & & & \\
Corrected Total & $27,480.688$ & 180 & &
\end{tabular}

Table 12. Grand mean (Dependent variable: Diversity_implementation).

\begin{tabular}{cccc}
\hline \multirow{2}{*}{ Mean } & \multirow{2}{*}{ Std. Error } & \multicolumn{2}{c}{$\mathbf{9 5 \%}$ Confidence Interval } \\
\cline { 3 - 4 } & & Lower Bound & Upper Bound \\
\hline 41.78 & 2.01 & 37.81 & 45.76 \\
\hline \multicolumn{3}{c}{ Resource: Research results. }
\end{tabular}

Table 13. Diversity management implementation by ownership. Dependent variable: Diversity_implementation.

\begin{tabular}{ccccc}
\hline \multirow{2}{*}{ Ownership } & \multirow{2}{*}{ Mean } & Std. Error & \multicolumn{2}{c}{ 95\% Confidence Interval } \\
\cline { 3 - 5 } & & & Lower Bound & Upper Bound \\
\hline private & 45.65 & 2.17 & 41.36 & 49.94 \\
public & 37.92 & 2.47 & 33.04 & 42.80 \\
\hline \multicolumn{3}{c}{ Source: Research results. }
\end{tabular}

Table 14. Diversity management implementation by size. Dependent variable: Diversity_implementation.

\begin{tabular}{ccccc}
\hline \multirow{2}{*}{ Size } & \multirow{2}{*}{ Mean } & \multirow{2}{*}{ Std. Error } & \multicolumn{2}{c}{$\mathbf{9 5 \%}$ Confidence Interval } \\
\cline { 4 - 5 } & & & Lower Bound & Upper Bound \\
\hline micro & 39.09 & 2.58 & 33.99 & 44.20 \\
small & 52.31 & 3.77 & 44.86 & 59.75 \\
middle & 33.91 & 2.24 & 29.48 & 38.34 \\
big & 41.82 & 2.42 & 37.05 & 46.59 \\
\hline
\end{tabular}

Source: Research results.

Table 15. Diversity management implementation by taken specialized management minimum of managers. Dependent variable: Diversity_implementation.

\begin{tabular}{ccccc}
\hline \multirow{2}{*}{ Specialized Manag. Minimum } & \multirow{2}{*}{ Mean } & Std. Error & \multicolumn{2}{c}{ 95\% Confidence Interval } \\
\cline { 4 - 5 } & & & Lower Bound & Upper Bound \\
\hline yes & 40.73 & 2.15 & 36.48 & 44.98 \\
no & 42.84 & 2.31 & 38.27 & 47.40 \\
\hline
\end{tabular}

Source: Research results. 
Table 16. Diversity management implementation by employee turnover. Dependent variable: Diversity_implementation.

\begin{tabular}{ccccc}
\hline \multirow{2}{*}{ Employee Turnover } & \multirow{2}{*}{ Mean } & Std. Error & \multicolumn{2}{c}{ 95\% Confidence Interval } \\
\cline { 4 - 5 } & & & Lower Bound & Upper Bound \\
\hline $0-5 \%$ & 41.12 & 2.05 & 37.07 & 45.17 \\
$6-10 \%$ & 43.19 & 1.80 & 39.64 & 46.75 \\
$11-20 \%$ & 41.03 & 3.88 & 33.37 & 48.70 \\
\hline \multicolumn{6}{c}{ Source: Research results. }
\end{tabular}

Table 17. Diversity management implementation and trend of employee satisfaction. Dependent variable: Diversity_implementation.

\begin{tabular}{ccccc}
\hline \multirow{2}{*}{ Employee Satisfaction-trend } & Mean & Std. Error & \multicolumn{2}{c}{ 95\% Confidence Interval } \\
\cline { 4 - 5 } & & & Lower Bound & Upper Bound \\
\hline unlisted & 38.36 & 1.75 & 34.91 & 41.82 \\
decreasing & 49.89 & 4.82 & 40.36 & 59.41 \\
not changing & 38.67 & 3.05 & 32.64 & 44.69 \\
Increasing & 40.22 & 2.62 & 35.04 & 45.39 \\
\hline
\end{tabular}

Source: Research results.

Table 18. Diversity management implementation and trend of patient satisfaction. Dependent variable: Diversity_implementation.

\begin{tabular}{ccccc}
\hline \multirow{2}{*}{ Patient Satisfaction-trend } & Mean & Std. Error & \multicolumn{2}{c}{$\mathbf{9 5 \% \text { Confidence Interval }}$} \\
\cline { 4 - 5 } & & & Lower Bound & Upper Bound \\
\hline unlisted & 40.21 & 2.05 & 36.16 & 44.26 \\
decreasing & 37.93 & 3.98 & 30.08 & 45.78 \\
not changing & 41.89 & 2.19 & 37.56 & 46.21 \\
Increasing & 47.10 & 2.68 & 41.82 & 52.39 \\
\hline
\end{tabular}

Source: Research results.

Table 19. Diversity management implementation and finance management (Dependent variable: Diversity_management).

\begin{tabular}{ccccccc}
\hline \multirow{2}{*}{ Parameter } & \multirow{2}{*}{ B } & Std. Error & t & Sig. & \multicolumn{2}{c}{$\mathbf{9 5 \% \text { Confidence Interval }}$} \\
\cline { 6 - 7 } & & & & & Lower Bound & Upper Bound \\
\hline Intercept & 38.617 & 5.126 & 7.533 & 0.000 & 28.496 & 48.738 \\
Finance management & 1.615 & 0.940 & 1.719 & 0.088 & 0.240 & 3.471 \\
\hline
\end{tabular}

Source: Research results.

The ownership factor was significant $(p=0.001)$, which means that private facilities have a higher level of diversity implementation. The organization size factor was also significant $(p=0.0001)$. In this case, however, the dependence is not linear as in attitudes to diversity. The highest level of diversity management implementation has small organizations.

The factor of completed specialization study of managers was not significant $(p>0.05)$, as well as the factor of employee turnover $(p>0.05)$.

The employee satisfaction factor was not significant $(p>0.05)$; while in the first question, it proved to be significant. Interestingly, in contrast to attitudes towards diversity, where dependence on employee satisfaction has been shown, the opposite is true in the case of diversity implementation. The patient satisfaction factor was identified as significant $(p=0.046)$. Healthcare facilities with increasing patient satisfaction have a significantly higher level of diversity implementation than the average of other categories. 
The dependence with the numerical variable finance management (i.e., the number of years in profit) was not significant in this case $(p>0.05)$.

\subsection{Mutual Correlations of Attitudes Towards Diversity and Diversity Management Implementation}

Subsequently, we evaluated the mutual correlation of the degree of implementation of diversity and attitudes to diversity. We used Pearson's coefficient. The significance level was $5 \%$ bilaterally.

Table 20 shows the significance of the correlation in the positive direction $(\mathrm{r}=0.557 p=0.0001)$, which means that organizations with a higher level of attitudes to diversity also show a higher rate of its implementation.

Table 20. Collerations between attitudes towards diversity and diversity management implementation.

\begin{tabular}{cccc}
\hline & & Attitudes_diversity & Diversity_implement. \\
\hline \multirow{3}{*}{ Attitudes_diversity } & Pearson Correlation & 1 & 0.557 \\
& Sig. (2-tailed) & & 0.000 \\
& N & 181 & 181 \\
\hline \multirow{3}{*}{ Diversity_implementation } & Pearson Correlation & 0.557 & 1 \\
& Sig. (2-tailed) & 0.000 & 181 \\
& $\mathrm{~N}$ & 181 & \\
\hline
\end{tabular}

Source: Research results.

At the same time, we can see that the organizations in the graph form two significant clusters (Figure 1). These clusters represent the affiliation of the organization according to the most important factor in the whole analysis, which is ownership: Public versus private.

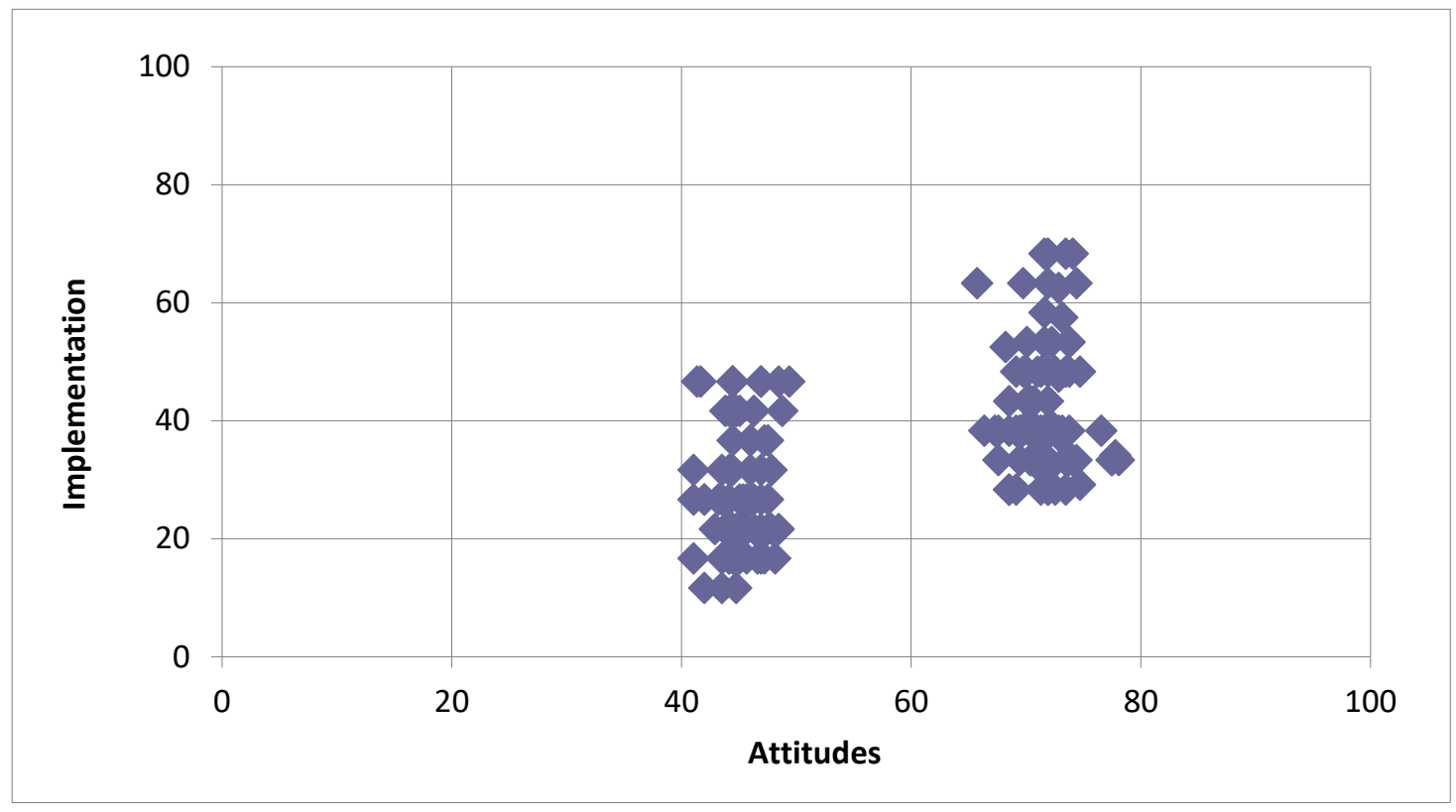

Figure 1. Diversity management implementation and attitudes towards diversity.

\section{Discussion}

Our research has shown that healthcare facility managers do not yet use diversity management as an effective management tool to achieve their management goals. At the same time, the dynamic and turbulent environment requires the readiness of organizations to handle unexpected situations. Management readiness is also linked to an effective use of a diverse workforce. The basic diversity management awareness is at a low level in the targeted facilities. Some tools are being used, 
but not conceptually, and unsystematically. The understanding and effective application of diversity management concept is chaotic, the basis diversity management models are not known, and the goals, activities, programs, responsibilities, and measurements are unexplored. The strong part of diversity management in the healthcare facilities is the diversity of working teams, which is in multiple studies being linked to a higher team performance $[22,54,60]$. As weak points were identified, the diversity as a part of organizational structure and diversity as a part of human resource management, even though multiple studies, are proving the positive impact of implemented organizational diversity on business performance $[33,34,44,55]$. Organizational culture is being perceived not only as an effect of diversity management, but also as a determinant of its implementation [68]. Diversity management in the field of human resource management is mostly understood as a tool with the aim to prevent discrimination in the context of the antidiscriminative legislation, also as a tool for diversity workforce management based on specific criteria (age, background, culture, nationality, religion, education, social class, etc.), and also as a tool for creating an equal opportunity and gender segmentation coordination. The topic of competence models of managers with a focus on diversity management is not clear. Swanson et al. [69], Walsh, Harrington, and Hines [70], and Pihlainen, Kivinen, and Lammintakanen [1] perceive the area of correct definition of competence models of managers as key in effective management of organizations.

Only to a small extent are special programs implemented, with focus on diversity being already implemented in the process of recruitment and subsequently in the process of development and maintenance of the workforce. Diversity education programs are implemented only sporadically and mainly in the area of non-discrimination legislation and in compliance with legal standards. Trainings for leader on team diversity management are also being sporadically provided. In other areas, such as dealing with otherness, integrating diversity into common processes and activities, or overcoming prejudices, there are no trainings being provided at all. Kundu, Bansal, and Chawla [71] explain the human resource diversity management framework, which demonstrates human resource practices at three levels, i. human resources strategy that values diversity, formalized human resources policy, measurement and audit of diversity, etc., tactical level (employment, training and development, evaluation and recognition) and operational level (staff training, communication networks, flexible employment, and support for work-life balance culture). Diversity management is thus a systematically planned commitment of organizations to recruit, retain, reward, and support employees' diversity.

Within diversity management models, healthcare facility managers prefer a relationship model that is characterized by a conscious effort to cultivate relationships between different groups. Their premise is that good relationships will help to overcome differences. This approach has the potential to build understanding and respect for differences. However, the fact is that it is often poorly understood and only used to minimize differences. This situation occurs when the relationship-building model is interpreted inaccurately, with a visible effort to focus primarily on highlighting similarities and avoiding the challenge related to actual diversity management. However, these organizations are very far away from a model of mutual adaptation that offers the best inclusion of diversity, based on acceptance and understanding of the differences and diversity of all parties involved. Primary goals of diversity management are seen by the managers of these institutions in beneficiary economic results, and partly also in attracting and retaining talent. Some studies point out mainly the performance improvement related to implementation of diversity management, but many go further and examine the benefits more comprehensively with respect to all stakeholders [22,39-41,44], which is not significantly considered in the healthcare facilities we studied.

Despite the fact that the initial situation was not optimal, we were able to create and apply the summarizing indices (Attitudes to Diversity and Implementation of Diversity Management) thanks to which we were able to define the current state in which the examined health care facilities are in relation to the application of diversity management. The aggregate index Attitudes to Diversity reached a higher average value than the index Implementation of Diversity Management. This means that the health care facilities managers and their internal mindset readiness in relation to the issue of diversity management exceed its real level of implementation. 
When evaluating the mutual correlation of the degree of implementation of diversity management and attitudes towards diversity, a significant correlation in a positive direction was found. Organizations with a higher level of attitudes towards diversity also have a higher degree of its implementation.

Ownership and size of the organization in terms of number of employees, employee satisfaction, and patient satisfaction were identified as significant variables. Private organizations providing health care achieve a higher level of attitudes towards diversity, and at the same time a higher level of implementation of diversity management. Attitudes towards diversity increase with the size of the organization. A linear contrast was identified. However, for the variable Implementation of diversity management, the dependence on the size of organizations is not linear as for attitudes towards diversity. It has been observed that the highest level of diversity management implementation occurs in small healthcare facilities.

The similar research realized Weech-Maldonado et al. [31]. They measured the cultural competence scores through 14 items in 119 California hospitals, finding that hospital ownership and size are important predictors of cultural competence activities, realized similar research. Another important factor, with implication on higher implementation of cultural competency tools, was the competitive business environment in which the hospitals operate. The Cultural Competency Assessment Tool of Hospitals (CCATH) score increased in parallel with the Herfindahl index.

The employee satisfaction factor was identified as significant only for the aggregate variable "Attitudes towards diversity". Facilities with increasing employee satisfaction have a significantly higher level of attitudes towards diversity than the average of other categories. It is interesting that, in contrast to attitudes towards diversity, where dependence was shown only with employee satisfaction, the implementation of diversity management was also identified as a significant factor in patient satisfaction. Healthcare facilities with increasing patient satisfaction have a significantly higher level of diversity implementation than the average of other categories. In relation to the economic results of the facilities, a positive dependence was found for the variable "Attitudes towards diversity". The factor was not significant for the variable "Diversity management implementation". This is in line with some studies, which point out that organizational performance is directly linked to diversity management only if diversity is managed effectively, meaning that diversity must be recognized, then managed, so that reducing disparities can improve organizational performance [29,38,45-47].

When examining the interrelationships between attitudes towards diversity and its implementation in organizations, their positive correlation was confirmed, while the ownership of the healthcare facility was identified as the most important criteria.

\section{Conclusions}

Our research was focused on the identification of the current state of knowledge and implementation of diversity management in facilities providing health care in Slovakia. It has implications for policy makers, as it points out the education importance of healthcare managers, who are typically top doctors, but often managers without the necessary managerial skills. Today's healthcare systems are very complex and work optimally with a constructive interconnection among their multiple stakeholders. On the other hand, it also brings implications for the public, as it points out the importance of implementing diversity management in increasing patient satisfaction. This research is one of the first studies focused on diversity management in the conditions of Slovak healthcare facilities. The modern management theories appeal on managers to coordinate the new diversity elements effectively. A diverse workforce is a source of cognitive diversity. Many studies have confirmed the positive effect of cognitive diversity in the context of an organization's ability to improve team processes, develop creativity, and create new innovative solutions [54,72,73]. Therefore, through diversity management, healthcare facilities can significantly influence their own innovative capacity, which can be a source of their competitiveness and business sustainability.

It was implemented in the form of a questionnaire and contained a complex of diverse questions, which focused on two key areas, namely the identification of attitudes to diversity and the diversity 
management implementation. The questions were developed by the research team to capture as much information as possible about diversity management. Some researchers may perceive our own structure of the procedure for calculating aggregate indices as subjective.

Other limitations of the research could include its implementation in Slovak conditions, which limits generalization. Nevertheless, Slovakia is a country with advanced health care, with quality services in the field of education and in the field of the diversity; management has many examples of good practice.

The number of respondents included 181 managers of health care facilities, which were different and relatively evenly represented in individual groups in terms of different criteria, which may represent, on the one hand, a limitation of the research due to the wider diversity of the sample. On the other hand, this is a pilot survey, unique in the conditions of the Slovak Republic, so a diverse sample allows mapping the situation in different environments and types of healthcare facilities.

Author Contributions: Conceptualization, Z.J., N.J.; methodology, Z.J., J.B.; software, N.J.; validation, Z.J., N.J., J.B.; formal analysis, Z.J.; investigation, J.B.; resources, K.P.; data curation, J.B., K.P.; writing-original draft preparation, Z.J., N.J.; writing - review and editing, K.P.; visualization, K.P.; supervision, N.J.; project administration, K.P.; funding acquisition, N.J. All authors have read and agreed to the published version of the manuscript.

Funding: This research was funded by grant related to VEGA MŠ No. 1/0017/20: Changes in the Application of Management Functions in the Context of the fourth Industrial Revolution and the Adaptation Processes of Companies in Slovakia.

Acknowledgments: This research was supported by project VEGA MŠ SR No. 1/0412/19: Human resource management systems in the era of Industry 4.0.

Conflicts of Interest: The authors declare no conflict of interest. The funders had no role in the design of the study; in the collection, analyses, or interpretation of data; in the writing of the manuscript, or in the decision to publish the results.

\section{Appendix A}

Table A1. The scoring system of selected items.

\begin{tabular}{|c|c|}
\hline Item of AD (Attitude toward Diversity) & Scoring System \\
\hline $\begin{array}{l}\text { Benefits perception of Diversity management } \\
\text { (1-no benefit, 7-maximum benefit) } \\
\text { - In sharing the knowledge and skills of diverse } \\
\text { - In the quality of the environment at all levels of the } \\
\text { organization for which the best workforce } \\
\text { would apply } \\
\text { - In increasing employee performance and engagement } \\
\text { by creating a highly inclusive work environment } \\
\text { - Innovative solutions due to the use of unique views, } \\
\text { skills, and perspectives of employees } \\
\text { - In increasing the quality of services provided }\end{array}$ & $\begin{array}{l}\text { Rating by answer from } 0 / 6 \text { to } 6 / 6 \text { points for each } \\
\text { item ascending }\end{array}$ \\
\hline $\begin{array}{l}\text { Barriers identification of Diversity Management } \\
\text { (1-not considered a barrier at all, 7-considered a } \\
\text { significant barrier) } \\
\text { - } \quad \text { Focus on other management priorities } \\
\text { - Only qualifications are taken as important when } \\
\text { recruiting staff } \\
\text { Weak awareness of the importance of } \\
\text { diversity management } \\
\text { - } \quad \text { Insufficient information and ambiguity in this area } \\
\text { - The complexity of monitoring and measurability of } \\
\text { - the results achieved } \\
\text { - Lack of funding for this purpose } \\
\text { Lack of time }\end{array}$ & $\begin{array}{l}\text { Rating by answer from } 0 / 6 \text { to } 6 / 6 \text { points for each } \\
\text { item descending }\end{array}$ \\
\hline
\end{tabular}


Table A1. Cont.

Opinion on statements about team work diversity:

(1-strongly agree, 7 -strongly disagree)

- The team diversity in terms of gender is very important

- The team diversity in terms of age is very important

- The absence of elderly workers is not linked to the absence of work experience

- The absence of elderly workers is not associated with a lower depth of knowledge

- The presence of "younger" workers is not associated with breaking stereotypes and a certain established routine

- The presence of "younger" workers is associated with a variety of approaches

- The presence of "younger" workers is associated with openness to the new and the ability to learn

- There should be no signs of ageism, or generational clashes and misunderstandings in the organization, where elderly employees are perceived as less productive than not flexible enough

- In the organization, young people should not be perceived as inexperienced, too ambitious, insufficiently erudite, threatening the elderly, and too often fluctuating

- Young childless leaders do not show a misunderstanding of the life situations of people with children

- Young leaders do not show a misunderstanding of the life situations of elderly people

Opinions on statements about diversity as a part of corporate culture:

(1-totally agree, 7-totally disagree)

- Diversity should be primarily a topic reflected on the part of both superiors and subordinates and a purposefully implemented principle

- The principles of diversity management are transferable to the organizational structure and culture of health care facilities

- Introduction of the concept of diversity into the organizational culture and setting up processes in the organization is necessary

- The concept of diversity should be included in the Code of Ethics. The concept of diversity should be addressed by trade unions

- education in the field of diversity, equal opportunities, etc. should be part of the educational activities in the organization

- The need for education is also necessary if the person is on maternity or parental leave

- It is essential to assess employee satisfaction as part of a diversity management policy

\section{Understanding of diversity management in context of}

human resource management

(1-totally agree, 7 -totally disagree)

- Management of a diverse workforce in terms of certain criteria (age, background, culture, nationality, religion, education, social class, ...)

- Equal opportunities policy and gender segmentation coordination

- Non-discrimination in the context of anti-discrimination legislation

- Inclusive organization
Rating by answer from $0 / 6$ to $6 / 6$ points for each item descending
Rating by answer from $0 / 6$ to $6 / 6$ points for each item descending
Rating by answer from $0 / 6$ to $6 / 6$ points for each item descending 
Table A1. Cont.

\begin{tabular}{ll}
\hline $\begin{array}{l}\text { Do managers' competency models also include diversity } \\
\text { management competencies? }\end{array}$ & $\begin{array}{l}\text { Yes-1 point } \\
\text { No, I don't know-0 points }\end{array}$ \\
\hline $\begin{array}{l}\text { The importance of individual manager competencies in } \\
\text { the diversity management }\end{array}$ \\
$\begin{array}{ll}\text { - The ability to treat, deal with, and work with people } \\
\text { fairly and equally, regardless of their nationality, race, } \\
\text { culture, disability, age, or gender }\end{array}$ \\
$\begin{array}{l}\text { - The ability to use and manage this diversity in the } \\
\text { best way, to promote equality in processes and }\end{array}$ & $\begin{array}{l}\text { Rating by answer from } 0 / 6 \text { to } 6 / 6 \text { points for each item } \\
\text { ascending }\end{array}$ \\
- The ability to drive innovation & \\
- The ability to understand others & \\
- The ability to build effective teams & \\
- The ability to ensure a work-life balance &
\end{tabular}

Evaluation of diversity importance for the success of the organization

(1-diversity is insignificant for us, 7-diversity is very

Rating by answer from $0 / 6$ to $6 / 6$ points per item important for us)

\begin{tabular}{ll}
\hline Item DI (Diversity implementation) & Scoring system \\
\hline Percentage of women in the company & $\begin{array}{l}\text { Range } 50-75 \%-1 \text { point } \\
\text { Otherwise- }-0 \text { point }\end{array}$ \\
\hline \multirow{2}{*}{ Employment of foreigners } & Yes- 1 point \\
No, I don't know- -0 point
\end{tabular}

Percentage of women in management.

- Women-top management

Range $30-75 \%$ - 1 point

- Women-middle management

- Women-low level management

Otherwise -0 point

\begin{tabular}{ll}
\hline Definition of diversity as a part of corporate strategy & Yes-1 point \\
& No, I don't know-0 point
\end{tabular}

Which groups of employees are targeted by diversity programs in the organization?

- Women

- Parents

- Maternity leaves and parental leaves

For each positive answer 1 point

- $\quad$ Foreign employees

- Handicapped

- $\quad$ LGBTI community

- Elderly employees

Do you implement programs of hiring, developing and Yes-1 point preserving of diversity workforce?

No, I don't know-0 point

Do you implement any of any of these diversity education programs?

- Antidiscrimination and compliance with legal standards

- Overcoming prejudices

- Training leaders to manage teams diversity

- Handling otherness

- Integrating diversity into common processes and activities

Evaluation of the current level implementation of diversity programs/elements in the organization (1-diversity is not applied at all, 7-diversity is fully applied)
Rating by answer from $0 / 6$ to $6 / 6$ points per item ascending 


\section{References}

1. Pihlainen, V.; Kivinen, T.; Lammintakanen, J. Management and leadership competence in hospitals: A systematic literature review. Leadersh. Health Serv. 2016, 29, 95-110. [CrossRef]

2. Ackerly, D.C.; Sangvai, D.G.; Udayakumar, K.; Shah, B.R.; Kalman, N.S.; Cho, A.H.; Schulman, K.A.; Fulkerson, W.J.; Dzau, V.J. Training the Next Generation of Physician-Executives: An Innovative Residency Pathway in Management and Leadership. Acad. Med. 2011, 86, 575-579. [CrossRef]

3. Enterkin, J.; Robb, E.; McLaren, S. Clinical leadership for high-quality care: Developing future ward leaders. J. Nurs. Manag. 2012, 21, 206-216. [CrossRef]

4. Yoder-Wise, P.S. The Future of Leadership. JONA: J. Nurs. Adm. 2014, 44, 318-320. [CrossRef]

5. McCallin, A.; Frankson, C. The role of the charge nurse manager: A descriptive exploratory study. J. Nurs. Manag. 2010, 18, 319-325. [CrossRef]

6. Townsend, K.; Wilkinson, A.; Bamber, G.J.; Allan, C. Accidental, unprepared, and unsupported: Clinical nurses becoming managers. Int. J. Hum. Resour. Manag. 2012, 23, 204-220. [CrossRef]

7. Dickinson, H.; Ham, C.; Snelling, I.; Spurgeon, P. Medical leadership arrangements in English healthcare organizations: Findings from a national survey and case studies of NHS trusts. Health Serv. Manag. 2013, 26, 119-125. [CrossRef] [PubMed]

8. Kuhlmann, E.; Von Knorring, M. Management and medicine: Why we need a new approach to the relationship. J. Health Serv. Res. Policy 2014, 19, 189-191. [CrossRef] [PubMed]

9. Lieu, T.A. Cultural Competence Policies and Other Predictors of Asthma Care Quality for Medicaid-Insured Children. Pediatrics 2004, 114, 102. [CrossRef] [PubMed]

10. Zeh, P.; Sandhu, H.K.; Cannaby, A.M.; Sturt, J.A. The impact of culturally competent diabetes care interventions for improving diabetes-related outcomes in ethnic minority groups: A systematic review. Diabet. Med. 2012, 29, 1237-1252. [CrossRef] [PubMed]

11. Weech-Maldonado, R.; Elliott, M.N.; Pradhan, R.; Schiller, C.; Dreachslin, J.; Hays, R.D. Moving towards culturally competent health systems: Organizational and market factors. Soc. Sci. Med. 2012, 75, 815-822. [CrossRef] [PubMed]

12. Avgar, A.C.; Givan, R.K.; Liu, M. Patient-Centered but Employee Delivered: Patient Care Innovation, Turnover Intentions, and Organizational Outcomes in Hospitals. ILR Rev. 2011, 64, 423-440. [CrossRef]

13. Havig, A.K.; Skogstad, A.; Veenstra, M.; Romøren, T.I. Real teams and their effect on the quality of care in nursing homes. BMC Health Serv. Res. 2013, 13, 499. [CrossRef] [PubMed]

14. Kurowski, A.; Gore, R.; Buchholz, B.; Punnett, L.A. Differences among nursing homes in outcomes of a safe resident handling program. J. Health Risk Manag. 2012, 32, 35-51. [CrossRef]

15. Managing an Intergenerational Workforce: Strategies for Health Care Transformation January 2014. Available online: www.aha.org/managing-ntergenerational-workforce (accessed on 10 December 2019).

16. Cook, F.L.; Bartram, T. Guest Editors Introduction: HRM in Health Care and Elderly Care: Current Challenges and toward a research Agenda. Hum. Resour. Manag. 2015, 54, 711-735. [CrossRef]

17. Kossek, E.E.; Lobel, S.; Brown, J. Human Resource Strategies to Manage Workforce Diversity: Examining 'The Business Case'. In Handbook of Workplace Diversity; SAGE Publications: Thousand Oaks, CA, USA, 2012; pp. 54-75.

18. Horwitz; Sonilal Improving health care quality through culturally competent physicians: Leadership and organizational diversity training. J. Health Leadersh. 2011, 3, 29. [CrossRef]

19. Büchner, V.A.; Schreyögg, J.; Schultz, C. The impact of the board's strategy-setting role on board-management relations and hospital performance. Health Care Manag. Rev. 2014, 39, 305-317. [CrossRef]

20. Baraias, B. 3 Ways Healthcare HR Can Use Diversity to Improve Patient Care. Available online: https: //www.precheck.com/blog/three-ways-healthcare-hr-can-use-diversity-to-improve-patient-care (accessed on 10 December 2019).

21. Moldogaziev, T.; Silvia, C. Fostering affective organizational commitment in public sector agencies: The significance of multifaceted leadership roles. Public Adm. 2014, 93, 557-575. [CrossRef]

22. Guillaume, Y.R.F.; Dawson, J.F.; Otaye-Ebede, L.; Woods, S.A.; West, M. Harnessing demographic differences in organizations: What moderates the effects of workplace diversity? J. Organ. Behav. 2015, 38, 276-303. [CrossRef] 
23. Van Knippenberg, D.; Van Ginkel, W.P.; Homan, A.C. Diversity mindsets and the performance of diverse teams. Organ. Behav. Hum. Decis. Process. 2013, 121, 183-193. [CrossRef]

24. Bin Bae, K.; Sabharwal, M.; Smith, A.E.; Berman, E. Does Demographic Dissimilarity Matter for Perceived Inclusion? Evidence from Public Sector Employees. Rev. Public Pers. Adm. 2016, 37, 4-22. [CrossRef]

25. Paustian-Underdahl, S.C.; King, E.B.; Rogelberg, S.G.; Kulich, C.; Gentry, W.A. Perceptions of supervisor support: Resolving paradoxical patterns across gender and race. J. Occup. Organ. Psychol. 2017, 90, 436-457. [CrossRef]

26. Randel, A.; Galvin, B.M.; Shore, L.M.; Ehrhart, K.H.; Chung, B.G.; Dean, M.A.; Kedharnath, U. Inclusive leadership: Realizing positive outcomes through belongingness and being valued for uniqueness. Hum. Resour. Manag. Rev. 2018, 28, 190-203. [CrossRef]

27. Ritz, A.; Alfes, K. Multicultural public administration: Effects of language diversity and dissimilarity on public employees' attachment to employment. Public Adm. 2017, 96, 84-103. [CrossRef]

28. Ashikali, T.; Groeneveld, S.; Kuipers, B. The Role of Inclusive Leadership in Supporting an Inclusive Climate in Diverse Public Sector Teams. Rev. Public Pers. Adm. 2020, 1-23. [CrossRef]

29. Sabharwal, M.; Levine, H.; D'Agostino, M. A Conceptual Content Analysis of 75 Years of Diversity Research in Public Administration. Rev. Public Pers. Adm. 2016, 38, 248-267. [CrossRef]

30. Dreachslin, J.L.; Weech-Maldonado, R.; Gail, J.; Epané, J.P.; Wainio, J.A. Blueprint for Sustainable Change in Diversity Management and Cultural Competence. J. Health Manag. 2017, 62, 171-183. [CrossRef]

31. Weech-Maldonado, R.; Elliott, M.; Pradhan, R.; Schiller, C.; Hall, A.; Hays, R.D. Can Hospital Cultural Competency Reduce Disparities in Patient Experiences with Care? Med. Care 2012, 50, S48-S55. [CrossRef]

32. Choi, S. Demographic Diversity of Managers and Employee Job Satisfaction. Rev. Public Pers. Adm. 2012, 33, 275-298. [CrossRef]

33. Opstrup, N.; Villadsen, A.R. The Right Mix? Gender Diversity in Top Management Teams and Financial Performance. Public Adm. Rev. 2014, 75, 291-301. [CrossRef]

34. Johansen, M.S.; Zhu, L. Who Values Diversity? Comparing the Effect of Manager Gender Across the Public, Private, and Nonprofit Sectors. Am. Rev. Public Adm. 2016, 47, 797-809. [CrossRef]

35. Pitts, D.; Hicklin, A.K.; Hawes, D.P.; Melton, E. What Drives the Implementation of Diversity Management Programs? Evidence from Public Organizations. J. Public Adm. Res. Theory 2010, 20, 867-886. [CrossRef]

36. Groeneveld, S.; Verbeek, S. Diversity policies in public and private sector organizations: An empirical comparison of incidence and effectiveness. Rev. Public Pers. Adm. 2012, 32, 353-381. [CrossRef]

37. Rühl, M. Die Relevanz von Diversity Management aus Unternehmensperspektive. In Handbuch Diversity Kompetenz; Genkova, P., Ringeisen, T., Eds.; Springer Fachmedien: Wiesbaden, Germany, 2016.

38. Horwitz, S.K.; Horwitz, I.B. The Effects of Team Diversity on Team Outcomes: A Meta-Analytic Review of Team Demography. J. Manag. 2007, 33, 987-1015. [CrossRef]

39. Andrevski, G.; Richard, O.C.; Shaw, J.D.; Ferrier, W.J. Racial Diversity and Firm Performance. J. Manag. 2011, 40, 820-844. [CrossRef]

40. Díaz-García, C.; Gonzalez-Moreno, Á.; Sáez-Martínez, F.J. Gender diversity within R\&D teams: Its impact on radicalness of innovation. Innovation 2013, 15, 149-160. [CrossRef]

41. Guillaume, Y.R.F.; Dawson, J.; Priola, V.; Sacramento, C.A.; Woods, S.A.; Higson, H.E.; Budhwar, P.S.; West, M. Managing diversity in organizations: An integrative model and agenda for future research. Eur. J. Work. Organ. Psychol. 2013, 23, 783-802. [CrossRef]

42. Ashikali, T.; Groeneveld, S. Diversity management in public organizations and its effects on affective commitment: The role of transformational leadership and inclusiveness of organizational culture. Rev. Public Pers. 2015, 35, 146-168. [CrossRef]

43. Andersen, S.C.; Moynihan, D.P. How Do Socially Distinctive Newcomers Fare? Evidence from a Field Experiment. Public Adm. Rev. 2018, 78, 874-882. [CrossRef]

44. Schaffer, B.S. Examining Reactions to Workplace Diversity: The Role of Dissimilarity-Attraction in Teams. Can. J. Adm. Sci. 2018, 36, 57-69. [CrossRef]

45. Kochan, T.; Bezrukova, K.; Ely, R.; Jackson, S.; Joshi, A.; Jehn, K.; Leonard, J.; Levine, D.; Thomas, D. The effects of diversity on business performance: Report of the diversity research network. Hum. Resour. Manag. 2003, 42, 3-21. [CrossRef]

46. Maznevski, M.L. Understanding Our Differences: Performance in Decision-Making Groups with Diverse Members. Hum. Relat. 1994, 47, 531-552. [CrossRef] 
47. Weech-Maldonado, R.; Dreachslin, J.L.; Epané, J.P.; Gail, J.; Gupta, S.; Wainio, J.A. Hospital cultural competency as a systematic organizational intervention: Key findings from the National Center for Healthcare Leadership diversity demonstration project. Health Care Manag. Rev. 2016, 43, 30-41. [CrossRef] [PubMed]

48. Galbraith, K.B. Practitioner Application. J. Health Manag. 2017, 62, 183-185. [CrossRef]

49. Watters, A.; Bergstrom, A.; Sandefer, R. Patient engagement and meaningful use: Assessing the impact of the ehr incentive program on cultural competence in healthcare. J. Cult. Divers. 2016, 23, 114-120.

50. Gonzalez, J.A. Relational Demography Between Managers and Stakeholders and Business Unit Performance. J. Leadersh. Organ. Stud. 2012, 19, 450-461. [CrossRef]

51. Kilduff, M.; Angelmar, R.; Mehra, A. Top Management-Team Diversity and Firm Performance: Examining the Role of Cognitions. Organ. Sci. 2000, 11, 21-34. [CrossRef]

52. Mitchell, R.; Boyle, B.; O’Brien, R.; Malik, A.; Tian, K.; Parker, V.; Giles, M.; Joyce, P.; Chiang, V.C. Balancing cognitive diversity and mutual understanding in multidisciplinary teams. Health Care Manag. Rev. 2017, 42, 1-52. [CrossRef]

53. Nowak, R. The effects of cognitive diversity and cohesiveness on absorptive capacity. Int. J. Innov. Manag. 2019, 24, 1-23. [CrossRef]

54. Hoever, I.J.; Van Knippenberg, D.; Van Ginkel, W.P.; Barkema, H.G. Fostering team creativity: Perspective taking as key to unlocking diversity's potential. J. Appl. Psychol. 2012, 97, 982-996. [CrossRef]

55. Javidan, M.; Teagarden, M.B. Conceptualizing and measuring global mindset. In Advances in Global Leadership; Emerald: Bingley, UK, 2011; Volume 6, pp. 13-39.

56. Genkova, P.; Schuster, D. Interkulturelle Kompetenz und Toleranz im Kontext von Diversity. Zeitschrift für Sozialmanagement 2014, 11, 23-38.

57. Moon, K.-K.; Christensen, R.K. Realizing the Performance Benefits of Workforce Diversity in the U.S. Federal Government: The Moderating Role of Diversity Climate. Public Pers. Manag. 2019, 49, 141-165. [CrossRef]

58. Liao, H.; Chuang, A.; Joshi, A. Perceived deep-level dissimilarity: Personality antecedents and impact on overall job attitude, helping, work withdrawal, and turnover. Organ. Behav. Hum. Decis. Process. 2008, 106, 106-124. [CrossRef]

59. Hafsi, T.; Turgut, G. Boardroom Diversity and its Effect on Social Performance: Conceptualization and Empirical Evidence. J. Bus. Ethic 2012, 112, 463-479. [CrossRef]

60. Vidhi, A. Managing the diversified team: Challenges and strategies for improving performance. Team Perform. Manag. Int. J. 2012, 18, 384-400.

61. Joshi, A.; Liao, H.; Roh, H. Bridging Domains in Workplace Demography Research: A Review and Reconceptualization. J. Manag. 2010, 37, 521-552. [CrossRef]

62. Harrison, D.A.; Klein, K.J. What's the difference? diversity constructs as separation, variety, or disparity in organizations. Acad. Manag. Rev. 2007, 32, 1199-1228. [CrossRef]

63. Dahlke, S.; Stahlke, S.; Coatsworth-Puspoky, R. Influence of Teamwork on Health Care Workers' Perceptions About Care Delivery and Job Satisfaction. J. Gerontol. Nurs. 2018, 44, 37-44. [CrossRef]

64. Kalisch, B.J.; Lee, K.H. The impact of teamwork on missed nursing care. Nurs. Outlook 2010, 58, $233-241$. [CrossRef]

65. Boone, C.; Hendriks, W. Top Management Team Diversity and Firm Performance: Moderators of Functional-Background and Locus-of-Control Diversity. Manag. Sci. 2009, 55, 165-180. [CrossRef]

66. Buyl, T.; Boone, C.; Hendriks, W.; Matthyssens, P. Top Management Team Functional Diversity and Firm Performance: The Moderating Role of CEO Characteristics. J. Manag. Stud. 2010, 48, 151-177. [CrossRef]

67. Boerner, S.; Linkohr, M.; Kiefer, S. Top management team diversity: Positive in the short run, but negative in the long run? Team Perform. Manag. Int. J. 2011, 17, 328-353. [CrossRef]

68. McCrea, A.M.; Zhu, L. The environmental determinants of diversity management: Competition, collaboration and clients. Public Adm. 2019, 97, 942-959. [CrossRef]

69. Swanson, E.; Kim, S.; Lee, S.-M.; Yang, J.-J.; Lee, Y.-K. The effect of leader competencies on knowledge sharing and job performance: Social capital theory. J. Hosp. Tour. Manag. 2020, 42, 88-96. [CrossRef]

70. Walsh, A.; Harrington, D.; Hines, P. Are hospital managers ready for value-based healthcare? A review of the management competence literature. Int. J. Organ. Anal. 2000, 28, 49-65. [CrossRef] 
71. Kundu, S.; Bansal, J.; Chawla, A. Managing Workforce Diversity through HR Practices: A Review. Available online: https://www.researchgate.net/publication/273064900_Managing_Workforce_Diversity_ through_HR_Practices_A_Review (accessed on 10 December 2019).

72. Wang, X.-H.; Kim, T.-Y.; Lee, D.-R. Cognitive diversity and team creativity: Effects of team intrinsic motivation and transformational leadership. J. Bus. Res. 2016, 69, 3231-3239. [CrossRef]

73. Aggarwal, I.; Woolley, A. Do you see what I see? The effect of members' cognitive styles on team processes and errors in task execution. Organ. Behav. Hum. Decis. Process. 2013, 122, 92-99. [CrossRef]

(C) 2020 by the authors. Licensee MDPI, Basel, Switzerland. This article is an open access article distributed under the terms and conditions of the Creative Commons Attribution (CC BY) license (http://creativecommons.org/licenses/by/4.0/). 